\title{
Quantitative structure-activity relationship (QSAR) investigation on 2-arylideneaminobenzimidazole derivatives as anti-proliferative activity against mv4-11 human leukaemia cells
}

\author{
Wisam A. Radhi ${ }^{1}$, Sadiq M. H. Ismael ${ }^{2, *}$, Jasim M. Al-Shawi ${ }^{2}$ and Kawkab A. Hussain ${ }^{2}$ \\ ${ }^{1}$ Department of Chemistry, Polymer Research Center, University of Basrah, Iraq \\ ${ }^{2}$ Department of Chemistry, College of Education, Pure Science, University of Basra, Iraq
}

\begin{abstract}
This undertaking involves QSAR investigations on the use of 28 2-arylideneaminobenzimidazole derivatives, for curbing the proliferative activity of cells in the mv4-11 human leukaemia cell line. The geometries of the compounds under investigation were initially optimized at level (PM3) in accordance to the semi-empirical theory, and subsequently through the B3LYP procedure at the 6-31G(d) basis set in accordance to the DFT theory. The multiple regression procedure was employed for the construction of two QSAR equations, to assess the anti-proliferative activity of these compounds (Equations 1 and 2). The values of $\mathrm{R}^{2}$ extended from 0.792 to 0.812 , those of $\mathrm{S}$ from 0.187 to 0.193 , and those of $\mathrm{F}$ from 24.897 to 30.429 . According to the results attained, the use of four parameters in Equation $2\left[\left(\mathrm{Q}_{\mathrm{N} 5}\right),\left(\mathrm{Q}_{\mathrm{N} 10}\right), \boldsymbol{r}\left(\mathbf{C}_{\mathbf{1}}=\mathbf{N}_{\mathbf{2}}\right)\right.$ andLUMO+4] led to raised $R^{2}$ values and minimized $S$ values. This suggests that these parameters are significant for identifying the anti-proliferative effectiveness of the compounds, in the context of mv4-11 human leukaemia cell line cells. This revelation is also an indication that QSAR can be successfully applied for a broad range of compounds.
\end{abstract}

Keywords: QSAR, 2-arylideneaminobenzimidazole, anti-proliferative, leukaemia cell line.

\section{Introduction}

The Mannich reaction is a well-established approach for the synthesis of biologically active compounds ${ }^{1}$. According to the results from several investigations, Mannich bases come with impressive analgesic ${ }^{2}$, anti-malarial ${ }^{3}$, anti-convulsant ${ }^{4,5}$, anti-psychotic ${ }^{6}$ or anti-microbial ${ }^{7-10}$ activities.

Biochemistry investigations, on the quantitative structure-activity relationship, frequently employ quantum chemical descriptors. The employment of these descriptors is well-documented in relevant literature ${ }^{11}$. The effectiveness of quantum chemical descriptors for QSAR development is attributed to their dependability, and flexibility, in the context of predictions. Calculations were carried out for the quantum molecular descriptors utilized in the QSAR investigations ${ }^{12}$. The employment of quantum chemical molecular descriptors for QSAR investigations, involve the use of semi-empirical techniques that include PM3 calculations ${ }^{13,14}$.

In the domain of medical chemistry, QSAR models are utilized for: predicting the toxicity of single cells in natural water ${ }^{15}$, fabricating narcotics and forecasting their toxicity ${ }^{16}$, subjecting natural isolated polyol esters to QSAR to determine the most favourable narcotic and insecticidal activities ${ }^{17}$, and

*Corresponding author: Sadiq M. H. Ismael

Email address: sadiq.ismael.si@gmail.com DOI: http://dx.doi.org/10.13171/mjc92190909835smhi enhancing the anti-cancer performance of 12 anticancer Schiff-based ligands ${ }^{18}$. The objective of this QSAR investigation is to gauge the activity of 28 2-arylideneaminobenzimidazole derivatives, in terms of opposition to the cells of the mv4-11 human leukaemia cell line.

\section{Theory}

Hardness $(\eta)$ and electronegativity $(\chi)$ are expressed as ${ }^{19}$ :

$\eta=\frac{1}{2}\left(\frac{\partial^{2} E}{\partial N^{2}}\right) V(r)=\frac{1}{2}\left(\frac{\partial \mu}{\partial N}\right) V(r)$

In which E represents the electronic energy, and V(r) represents the external potential, of an N-electron scheme. Through the Koopmans' theorem for closed-shell molecules, $\eta$ and $\chi$ can be expressed as ${ }^{20}$ :

$$
\begin{aligned}
& \eta=(I-A)=1 / 2(\varepsilon L U M O-\varepsilon H O M O) \\
& \chi=\frac{1}{2}(I+A) \\
& I=- \text { sHOMO and } A=-\varepsilon L U M O
\end{aligned}
$$




\section{Experimental}

\subsection{Optimization of models and geometry}

Quantum chemical computations were conducted for 28 2-arylideneaminobenzimidazolederivatives. The semi-empirical PM3 procedure in the Hyperchem programme 8.0 (www.hyper.com) was employed to realize the ultimate geometries. The PCGamess programme ${ }^{21}$ was used, to subject the consequential optimized geometries, to supplementary single point computations at the B3LYP/6-31G(d) level of the theory. B3LYP denotes a blending of the hybrid exchange of Becke ${ }^{22}$, with the functional correlation gradient of Lee and Yang ${ }^{23}$. Information on the experimental anti-proliferative features, regarding the 28 compounds under investigation, was derived from reference ${ }^{24}$. Figure 1 shows chemical structure of compound 1 and Table 2 exhibit the configurations of the 28 compounds. Table 2 exhibit the configurations of the 28 compounds.

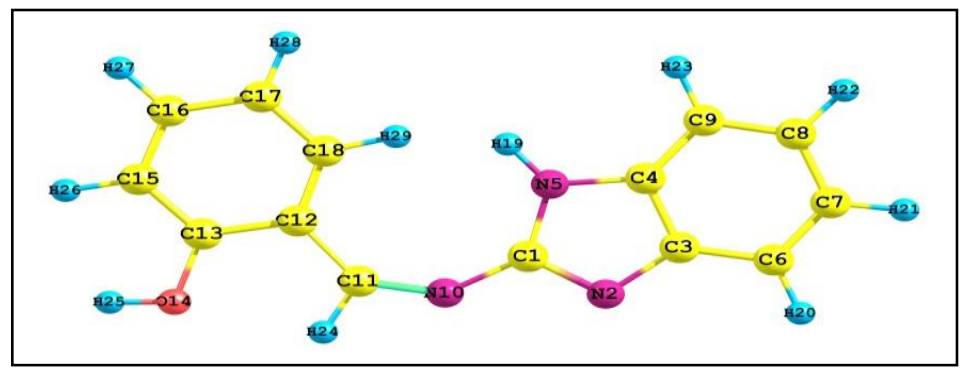

Figure 1. Chemical structure of compound 1<smiles>[Al]C=Nc1nc2ccccc2[nH]1</smiles>

$1-4$<smiles>[Al]=Nc1nc2ccccc2n1CN1CCOCC1</smiles>

$10,13,15$<smiles>[Al]=C(N=[V])N=Cc1nc2ccccc2n1CN1CCN(c2ccccn2)CC1</smiles>

17,21<smiles>[Al]CNc1nc2ccccc2n1CN1CCCCC1</smiles>

24<smiles>[Al]CNc1nc2ccccc2[nH]1</smiles>

$5-8$<smiles>CN1CCN(Cn2c(N=CC=[V])nc3ccccc32)CC1</smiles>

11<smiles>C=Nc1nc2ccccc2n1CN1CCN(c2ccccc2OC)CC1</smiles>

18,22

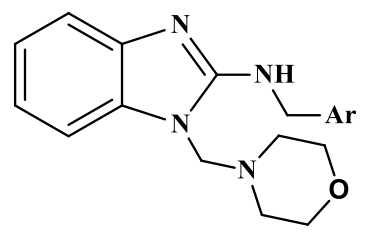

25,26<smiles>N#CC1=C(N)n2c(nc3ccccc32)NC1[Al]</smiles><smiles>C1=CN=C(C=Nc2nc3ccccc3n2CN2CCCCC2)CC1</smiles>

$9,12,14,19$<smiles>[Al]=Nc1nc2ccccc2n1CN1CCN(c2ccccc2)CC1</smiles>

16,20<smiles>[Al]=Cc1nc2ccccc2n1CN1CCN(c2ncccn2)CC1</smiles>

23<smiles>[R]C(=O)C1C([Al])Nc2nc3ccccc3n2C1C</smiles>

27

Figure 2. Chemical Structures of compounds 
Table 1. The target compounds.

\begin{tabular}{|l|l|}
\hline No. of compounds & \\
\hline $2,6,12,13,26,27,28$ \\
\hline $4,9,9,10,11,24,25$
\end{tabular}

\section{Results and Discussion}

The parameters listed in Table 2 were considered for this investigation. In order to ascertain the statistical correlation, the physiochemical parameters were deemed independent variables, while the antiproliferative activity was deemed a dependent variable. The generation of the statistically significant models, was achieved through the transference of data to the statistical programme datafit (version 9.0.59). The descriptors specified in Table 2 were employed to facilitate the formation of the predictive model. These descriptors were used for the computation of the Schiff-bases under investigation ${ }^{25}$. Two QSAR models for the 28 2 -arylideneaminobenzimidazole derivatives were generated, and parametrically represented in Equations 1 and 2, with the correlation coefficient $\mathrm{R}^{2}=0.792-0.812$. It has been established, that a satisfactory predictive performance, can be realized through a MLR model that possesses elevated $\mathrm{R}^{2}$ and Fisher ratio $(\mathrm{F})$ values, a reduced standard error (S) and a minimum descriptor count ${ }^{26,27}$.

This original model, which relies on just three descriptors [Q $\left.\left.\mathrm{Q}_{\mathrm{N} 5}\right), \quad r\left(\mathrm{Q}_{\mathrm{N} 10}\right), \mathrm{LUMO}+4\right]$ offers correlation coefficient $\mathrm{R}^{2}$ values of 0.792 . This is illustrated in Equation 1.

pIC50= $2.582\left(\mathrm{Q}_{\mathrm{N} 5}\right)-4.596\left(\mathrm{Q}_{\mathrm{N} 10}\right)-0.922(\mathrm{LUMO}+4)$ $+2.194(1)$

The statistical features of the constructed equation are as follows:

$\mathrm{R}^{2}=0.792, \quad \mathrm{Ra} \wedge 2=0.765, \mathrm{~S}=0.193, \quad \mathrm{~F}=30.429$ $\mathrm{Q}^{2}=0.793$

The correlation between experimental $\mathrm{pIC}_{50}$ and predicted $\mathrm{pIC}_{50}$ in Equation 1 is depicted in Figure 3.

The quality of models can be evaluated by correlation coefficient squared $\left(\mathrm{R}^{2}\right)$, coefficient of determination, or in the best, by internal validation. Internal model validation was carried out using leave-one-out (LOO-Q2) method. For calculating Q2, each sample in the training set was eliminated once and the activity of the eliminated sample was predicted by using the model developed by the remaining samples. The $\mathrm{Q}^{2}$ computed using the expression which explains the internal strength of a model. A model is considered acceptable when the value of Q2 exceeds $0.5^{28}$.

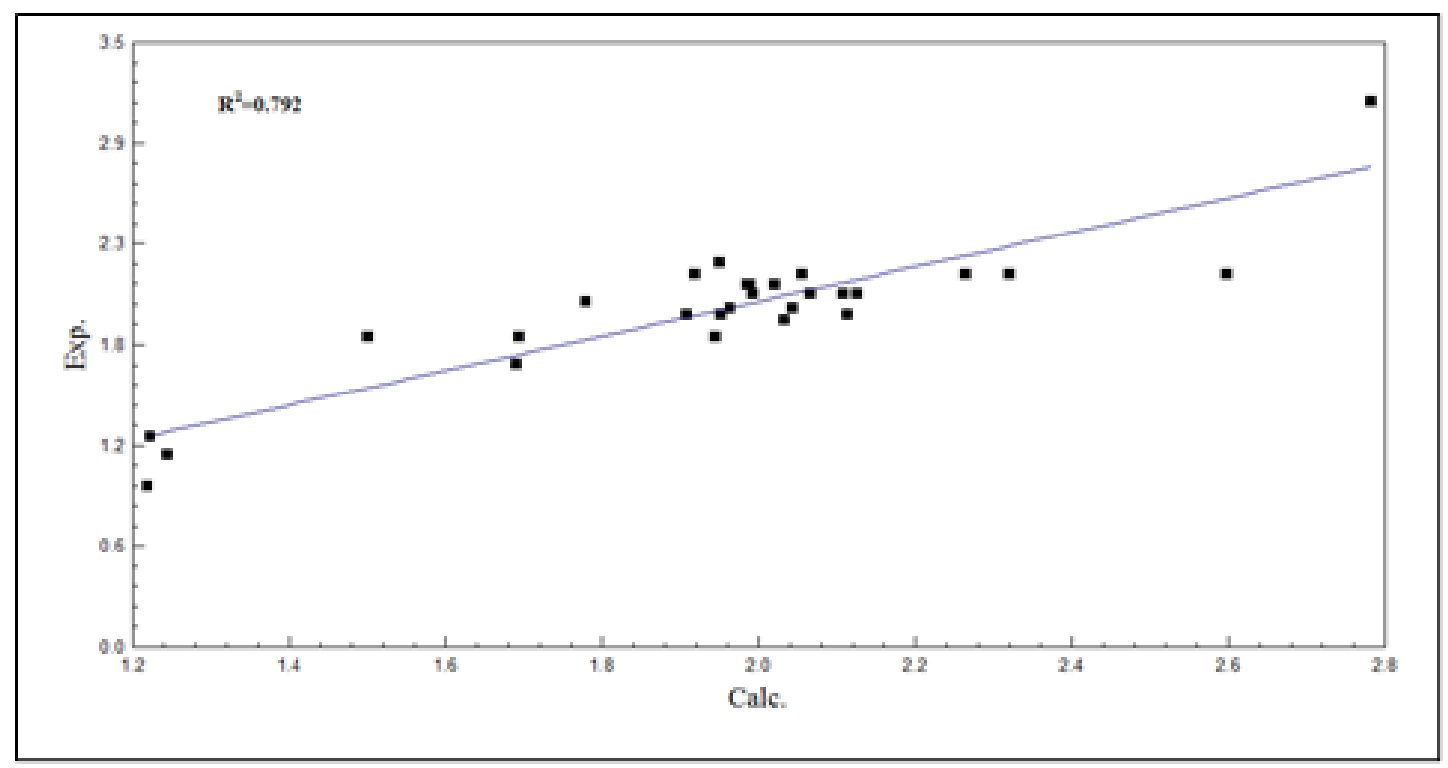

Figure 3. Plot of The antiproliferative activity of compounds against the cells of MV4-11 human leukemia cell line prediction versus the antiproliferative activity of compounds against the cells of MV4-11 human leukemia cell line experimental using Eq1 
In Equation 2, the substitution of the $r(\mathrm{C} 1=\mathrm{N} 2)$ descriptor led to the realization of an excellent correlation coefficient $\mathrm{R}^{2}$. Also, the reduced standard error in Equation 2 was observed to be comparable, to the reduced standard error in Equation 1.

$\mathrm{pIC} 50=2.905\left(\mathrm{Q}_{\mathrm{N} 5}\right)-4.706\left(\mathrm{Q}_{\mathrm{N} 10}\right)+1.738 r(\mathrm{C} 1=\mathrm{N} 2)-$ $0.908(\mathrm{LUMO}+4)-2.058$ (2)

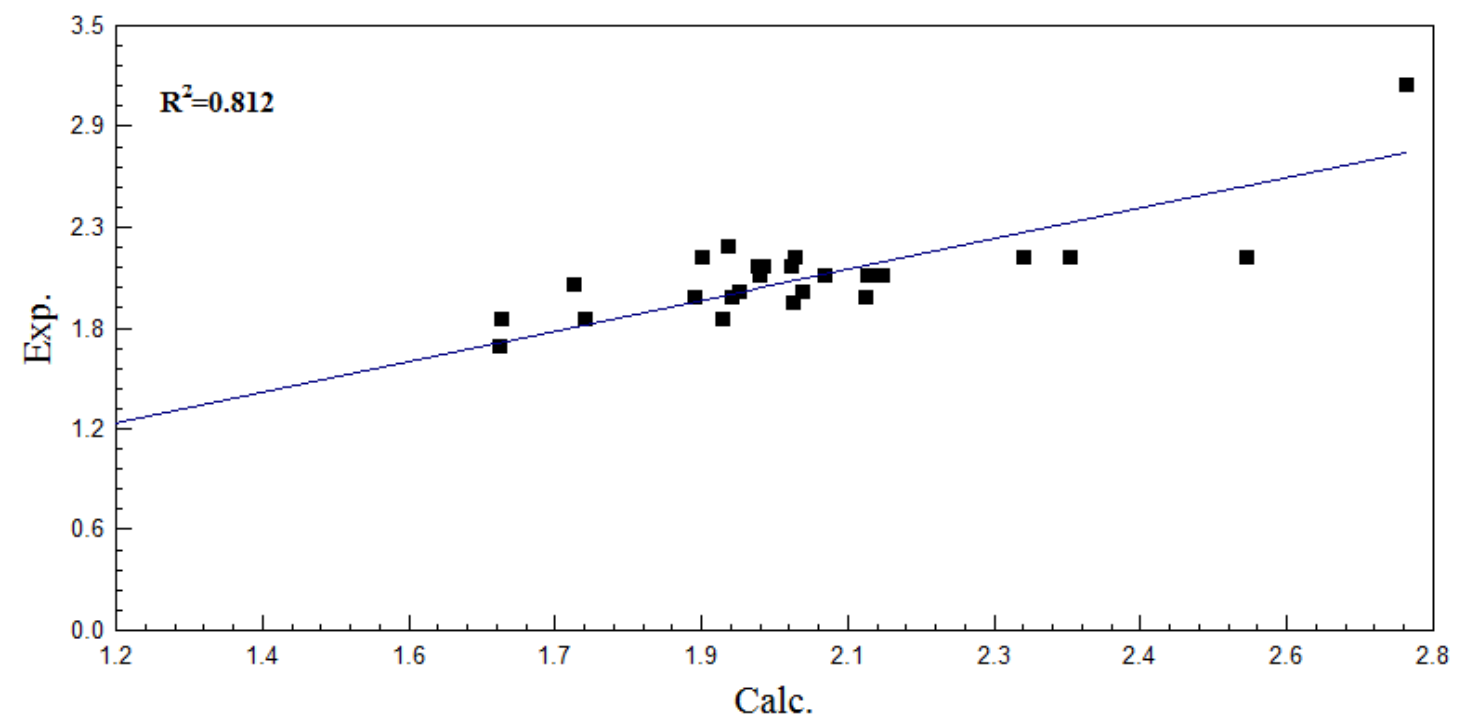

Figure 4. Plot of The antiproliferative activity of compounds against the cells of MV4-11 human leukemia cell line prediction versus The antiproliferative activity of compounds against the cells of MV4-11 human leukemia
The statistical characteristics of the constructed equation are as follows:

$\mathrm{R}^{2}=0.812, \mathrm{Ra}^{\wedge} 2=0.779, \mathrm{~S}=0.187, \mathrm{~F}=24.897$ $\mathrm{Q}^{2}=0.814$

Figure 4. Present the relationships between experimental $\mathrm{pIC}_{50}$ and predicted $\mathrm{pIC}_{50}$ by $\mathrm{Eq} 2$.

$$
\text { cell line experimental using Eq2 }
$$


Table 2. Descriptors as the independent variables used for QSAR analysis of compounds.

\begin{tabular}{|c|c|c|c|c|c|c|c|c|c|c|c|c|c|c|}
\hline Comp. & $\log P$ & $r\left(\mathrm{C}_{1}=\mathrm{N}_{2}\right)$ & H.E & $Q_{N 10}$ & $Q_{\text {N5 }}$ & LUMO+4 & HOMO-1 & HOMO & LUMO & E.GAP & $I$ & $\boldsymbol{A}$ & $\mathbf{X}$ & $\eta$ \\
\hline 1 & -0.03 & 1.351 & 1.351 & -0.423 & -0.761 & 1.034 & -6.092 & -5.681 & -1.981 & 3.7 & 5.681 & 1.981 & 3.831 & 1.85 \\
\hline 2 & -0.03 & 1.349 & 1.349 & -0.430 & -0.761 & 1.069 & -6.125 & -5.687 & -1.902 & 3.785 & 5.687 & 1.902 & 3.7945 & 1.8925 \\
\hline 3 & -0.03 & 1.351 & 1.351 & -0.425 & -0.758 & 1.023 & -6.168 & -5.809 & -2.057 & 3.752 & 5.809 & 2.057 & 3.933 & 1.876 \\
\hline 4 & 0.77 & 1.533 & 1.533 & -0.448 & -0.747 & 0.895 & -6.345 & -5.722 & -2.438 & 3.284 & 5.722 & 2.438 & 4.08 & 1.642 \\
\hline 5 & -0.21 & 1.342 & 1.342 & -0.638 & -0.719 & 1.616 & -5.986 & -5.393 & -0.071 & 5.322 & 5.393 & 0.071 & 2.732 & 2.661 \\
\hline 6 & -0.21 & 1.342 & 1.342 & -0.622 & -0.721 & 1.627 & -5.94 & -5.357 & -0.122 & 5.235 & 5.357 & 0.122 & 2.7395 & 2.6175 \\
\hline 7 & -0.21 & 1.342 & 1.342 & -0.626 & -0.721 & 1.644 & -5.989 & -5.363 & -0.101 & 5.262 & 5.363 & 0.101 & 2.732 & 2.631 \\
\hline 8 & 0.59 & 1.34 & 1.34 & -0.636 & -0.721 & 1.301 & -6.06 & -5.504 & -0.378 & 5.126 & 5.504 & 0.378 & 2.941 & 2.563 \\
\hline 9 & 1.28 & 1.341 & 1.341 & -0.422 & -0.554 & 0.854 & -5.654 & -5.341 & -1.597 & 3.744 & 5.341 & 1.597 & 3.469 & 1.872 \\
\hline 10 & 0.22 & 1.343 & 1.343 & -0.423 & -0.546 & 0.805 & -5.812 & -5.436 & -1.284 & 4.152 & 5.436 & 1.284 & 3.36 & 2.076 \\
\hline 11 & 0.36 & 1.341 & 1.341 & -0.424 & -0.550 & 0.841 & -5.391 & -5.055 & -1.445 & 3.61 & 5.055 & 1.445 & 3.25 & 1.805 \\
\hline 12 & 1.28 & 1.342 & 1.342 & -0.423 & -0.553 & 0.825 & -5.712 & -5.372 & -1.458 & 3.914 & 5.372 & 1.458 & 3.415 & 1.957 \\
\hline 13 & 0.22 & 1.341 & 1.341 & -0.428 & -0.540 & 0.71 & -5.869 & -5.513 & -1.355 & 4.158 & 5.513 & 1.355 & 3.434 & 2.079 \\
\hline 14 & 1.28 & 1.343 & 1.343 & -0.420 & -0.543 & 0.762 & -5.757 & -5.485 & -1.488 & 3.997 & 5.485 & 1.488 & 3.4865 & 1.9985 \\
\hline 15 & 0.22 & 1.341 & 1.341 & -0.423 & -0.542 & 0.729 & -5.861 & -5.532 & -1.387 & 4.145 & 5.532 & 1.387 & 3.4595 & 2.0725 \\
\hline 16 & 0.85 & 1.339 & 1.339 & -0.419 & -0.553 & 0.762 & -5.652 & -5.461 & -1.809 & 3.652 & 5.461 & 1.809 & 3.635 & 1.826 \\
\hline 17 & 0.82 & 1.342 & 1.342 & -0.418 & -0.554 & 0.846 & -5.624 & -5.368 & -1.491 & 3.877 & 5.368 & 1.491 & 3.4295 & 1.9385 \\
\hline 18 & -0.14 & 1.339 & 1.339 & -0.417 & -0.552 & 0.607 & -5.624 & -5.483 & -1.776 & 3.707 & 5.483 & 1.776 & 3.6295 & 1.8535 \\
\hline 19 & 2.08 & 1.34 & 1.34 & -0.413 & -0.554 & 0.729 & -5.741 & -5.488 & -1.877 & 3.611 & 5.488 & 1.877 & 3.6825 & 1.8055 \\
\hline 20 & 1.66 & 1.341 & 1.341 & -0.410 & -0.552 & 0.77 & -5.681 & -5.534 & -1.733 & 3.801 & 5.534 & 1.733 & 3.6335 & 1.9005 \\
\hline 21 & 1.62 & 1.342 & 1.342 & -0.412 & -0.556 & 0.748 & -5.665 & -5.483 & -1.929 & 3.554 & 5.483 & 1.929 & 3.706 & 1.777 \\
\hline 22 & 0.66 & 1.34 & 1.34 & -0.407 & -0.554 & 0.65 & -5.671 & -5.586 & -2.029 & 3.557 & 5.586 & 2.029 & 3.8075 & 1.7785 \\
\hline 23 & 1.44 & 1.341 & 1.341 & -0.414 & -0.555 & 0.672 & -5.766 & -5.564 & -1.94 & 3.624 & 5.564 & 1.94 & 3.752 & 1.812 \\
\hline 24 & 1.1 & 1.344 & 1.344 & -0.639 & -0.545 & 1.583 & -5.66 & -5.619 & -0.31 & 5.309 & 5.619 & 0.31 & 2.9645 & 2.6545 \\
\hline 25 & 0.04 & 1.344 & 1.344 & -0.631 & -0.588 & 1.592 & -5.828 & -5.338 & -0.155 & 5.183 & 5.338 & 0.155 & 2.7465 & 2.5915 \\
\hline 26 & 0.04 & 1.349 & 1.349 & -0.651 & -0.568 & 1.518 & -5.766 & -4.982 & 0.323 & 5.305 & 4.982 & -0.323 & 2.3295 & 2.6525 \\
\hline 27 & 0.93 & 1.342 & 1.342 & -0.638 & -0.693 & 0.8 & -5.719 & -5.421 & -1.619 & 3.802 & 5.421 & 1.619 & 3.52 & 1.901 \\
\hline 28 & -0.48 & 1.34 & 1.34 & -0.644 & -0.651 & 0.748 & -5.981 & -5.698 & -1.134 & 4.564 & 5.698 & 1.134 & 3.416 & 2.282 \\
\hline
\end{tabular}

Definition of Descriptors Used in This Study: E.Gap = Different between HOMO and LUMO is energy gaps in eV, HOMO = The energy of Highest Occupied Molecular Orbital in eV, LUMO = The energy of Lowest Unoccupied Molecular Orbital in eV,,$\chi=$ Electronegative in ev, $\mathrm{r}(\mathrm{C} 1=\mathrm{N} 2)=$ distance between $\mathrm{C} 1$ atom and $\mathrm{N} 2$ atom by angstrom, $\left(\mathrm{Q}_{\mathrm{N} 5}\right)$ : Charge of $\mathrm{N} 5$ atom, $\left(\mathrm{Q}_{\mathrm{N} 10}\right)$ : Charge of $\mathrm{N} 10$ atom, $\mathrm{I}=$ ionization potential in $\mathrm{eV}, \mathrm{A}=$ electron affinity in $\mathrm{eV}$. 
In all equations above, it can be seen the negative values of descriptors suggests that the activity of the compounds under study is decreases with increasing values of these descriptors. The variance inflation factors (VIF) for the descriptors in Equations 1 and 2 are provided in Table 3. In all these equations, the VIF for the descriptors $\mathrm{Q}_{\mathrm{N} 5}, \mathrm{Q}_{\mathrm{N} 10}, \mathrm{LUMO}+4$ and $r(\mathrm{C} 1=2 \mathrm{~N})$ is considered relatively substantial.

Table 3. The varied inflation factor (VIF) quantifies the severity of multicollinearity least squares regression analysis.

\begin{tabular}{|l|l|l|}
\hline \multicolumn{1}{|c|}{ Equations } & & \\
\cline { 1 - 2 } Descriptor & \multirow{2}{*}{ Eq.1 } & \multirow{2}{*}{ Eq.2 } \\
& & \\
\hline $\mathrm{Q}_{\mathrm{N} 5}$ & 1.251 & 1.490 \\
\hline $\mathrm{Q}_{\mathrm{N} 10}$ & 2.506 & 2.545 \\
\hline LUMO+4 & 2.686 & 2.694 \\
\hline$r(\mathrm{C} 1=2 \mathrm{~N})$ & - & 1.201 \\
\hline
\end{tabular}

\section{Conclusion}

The use of quantum chemical calculated parameters, can pave the way towards the realization of a QSAR, with the capacity to forecast the anti-proliferative activity of compounds, with regards to the cells of the mv4-11human leukaemia cell line. According to the results derived through this investigation, the modelling of anti-proliferative activity, for 2arylideneaminobenzimidazole derivatives, is achievable through multiple linear regression (MLR). Among the models generated during this endeavour, the model derived by way of Equation 2, with $\mathrm{R}^{2}=0.812, \mathrm{Ra}^{\wedge} 2=0.779, \mathrm{~S}=0.187$ and $\mathrm{F}=24.897$, proved superior.

\section{References}

1- G. Aljohani, M.A. Said, D. Lentz, N. Basar, A. Albar, S.Y. Alraqa and Adeeb A. Ali, Microwave-Assisted Synthesis of Mono- and Disubstituted 4-Hydroxyacetophenone Derivatives via Mannich Reaction: Synthesis, XRD and HS-Analysis, Molecules, 2019, 24, $1-14$.

2- A. Balakrishnan and A. Sankar, Study on the Synthesis, Characterization and Antimicrobial Activity of the New Mannich Base Benzimidazolyl Phenyl Methyl Acetamide and its Metal Complexes, International Journal of Pharmacy and Pharmaceutical Research, 2017, 10(2), 60-68.

3- G. Jinky, C. Dipak, K.K. Mukesh, R. Mithun, Synthesis and Antimalarial Activity Evaluation of some Mannich Bases of Tetraoxane-Phenol Conjugate, Indian Journal of Pharmaceutical Education and Research, 2016, 50(4), 591-597.

4- A.K. Keshari, A. Tewari, S.S. Verma, S.K. Saraf, Novel Mannich-bases as Potential Anticonvulsants: Syntheses, Characterization and
Biological Evaluation, Central Nervous System Agents in Medicinal Chemistry, 2017, 17(3), 219-228.

5- K. Kamioski, J. Obniska, I. Chlebek, P. Liana, E. PIkala, Synthesis and biological properties of new $\mathrm{N}$-Mannich bases derived from 3-methyl-3phenyl- and 3,3-dimethyl-succinimides. Part V, Eur. J. Med. Chem., 2013, 66,12-21.

6- S. Linz, J. Muller, H. Hubner, P. Gmeiner, R. Troschutz, Design, synthesis and dopamine D4 receptor binding activities of new $\mathrm{N}$-heteroaromatic 5/6-ring Mannich bases ,Bioorg. Med. Chem., 2009, 17, 4448-4458.

7- T. Plech, M. Wujec, M. Majewska, U. Kosikowska, A. Malm, microbiologically active Mannich bases derived from 1,2,4triazoles. The effect of C-5 substituent on antibacterial activity, Med. Chem. Res., 2013, 22, 2531-2537.

8- A. Idhayadhulla, R.S. Kumar, A.J. Abdul Nasser, J. Selvin and A. Manilal, Synthesis of some Mannich base derivatives and their antimicrobial activity study, Arabian Journal of Chemistry, 2014, 7, 994-999.

9- S.N. Kanchana, V. Burra and L.K. Ravindra Nath, Novel Synthesis and Anti-Microbial Activity Study of Innovative Mannich Bases Containing 2-Phenoxy-1,3, 2-dioxa Phospholanes and Indole Systems, 2014, 30(3), 1349-1360.

10-L. Popiołek, A. Biernasiuk, K. Paruch, P. Patrejko, M. Wujec, Synthesis and evaluation of antimicrobial properties of new Mannich bases of 4,5-disubstituted-1,2,4-triazole-3thiones, 2014, 192(7), 880-885.

11-V. Ravichandran, R. Harish, QSAR studies on imidazoles and sulfonamides as antidiabetic agents, Ovidius University Annals of Chemistry, 2019, 30(1), 5-13.

12-M.T. Ibrahim, A. Uzairu, G.A. Shallangwa, S. Uba, QSAR modelling and docking analysis of some thiazole analogues as $\alpha$-glucosidase inhibitors, The Journal of Engineering and Exact Sciences, 2019, 5(3), 257-270.

13-O.A. Hatem, Computational Chemistry Application of Physicochemical Descriptors: QSAR Study on Some $\beta$-Carboline Compounds, Der Pharma Chemica, 2017, 9(8), 150-156.

14-N.A. Saleh, The QSAR and docking calculations of fullerene derivatives as HIV-1 protease inhibitors, Spectrochimica Acta Part A: Molecular and Biomolecular Spectroscopy, 2015, 136, 1523-1529.

15-J.H. Al-Fahemi, D.L. Cooper, N.L. Allan, CroaticaChemicaActa, Predictions of Toxicity to Chlorella vulgaris and the Use of Momentumspace Descriptors, 2009, 82, 311-316.

16-L. Chang, C.M. Chang, A QSAR Study on the Persistence of Fungicides in the Environment, International Journal of Quantitative StructureProperty Relationships, 2019, 4(2),100-116.

17-W. Shao-peng, J. Zhi-qin, Z. Hui-xiao, Z. Ji-wen, W. Yong-hua, W. Wen-jun, Isolation, biological 
evaluation and 3D-QSAR studies of insecticidal/narcotic sesquiterpene polyol esters, Journal of Molecular Modeling, 2011, 17, 681-693.

18-K.A. Hussain, W. A-H Radhi, S. M-H. Ismael, Quantitative Structure-Activity Relationships (QSAR) study and improving it of some Schiffbase ligands as anticancer for prostate cancer, Journal of Chemical and Pharmaceutical Research, 2012, 4, 1702-1707.

19-B. Bultink, W. Langenaeker, R. Carbo-dorca, J.P. Tollenaere, Fast Calculation of Quantum Chemical Molecular Descriptors from the Electronegativity Equalization Method. J. Chem. Inf. Compt. Sci., 2003, 43, 422-428.

20-Y. Xia, D. Yin, C. Rong, Q. Xu, D. Yin, S. Liu, Impact of Lewis Acids on Diels-Alder Reaction Reactivity: A Conceptual Density Functional Theory Study, J. Phys. Chem. A, 2008, 112, 9970-9977.

21-A.G. Alex, Firefly version 8, www http://classic.chem.msu.su/gran/firefly/index.htm.

22-A.D. Becke, Density-functional thermochemistry. V. Systematic optimization of exchangecorrelation functionals, Density-functional thermochemistry. V. Systematic optimization of exchange-correlation functionals, J. Chem. Phys., 1997, 107, 8554-8560.

23-C. Lee, W. Yang, R.G. Parr, Development of the Colle-Salvetti correlation-energy formula into a functional of the electron density, Phys. Rev. B: Condents. Matter Mater. Phys., 1988, 37, 785-789.

24- A. Nowicka, H. Liszkiewicz, W. Nawrocka, J. Ietrzyk, J. Sadowska, Synthesis and in vitro antiproliferative activity of novel 2arylideneaminobenzimidazole, actapoloniaepharm aceutica - drug research, 2015, 72, 951-963.

25-K. Baumann, Uniform-length molecular descriptors for quantitative structure-property relationships (QSPR) and quantitative structureactivity relationships (QSAR): classification studies and similarity searching, J. Anal. Chem., 1999, 18, 36-41.

26-R. Veerasamy, H. Rajak, A. Jain, S. Sivadasan, C. P. Varghese and R.K. Agrawal, Validation of QSAR Models - Strategies and Importance, International Journal of Drug Design and Discovery, 2011, 2(3), 511-519.

27-D.L. Massart, B.G. Vandeginste, L.M. Buydens, S.D. Jong, P.J. Lewi, J. Smeyers-Verbeke, "Handbook of Chemometrics and Qualimetrics: Part A", Elsevier, Amsterdam, 1997.

28-W.A. Radhi, S.M.H. Ismael, J.M. Al-Shawi, K.A. Hussein, Quantitative Structure-Activity Relationship Studies of Flavonoids Substituted as Anticancer Agents Activity against the Growth of the Hepatic Cancer Cell lines HepG2,

International Journal of Chemistry, 2017, 9, 1-9. 